\title{
http://bjas.journals.ekb.eg \\ Evaluation of Serum Levels of 25-hydroxy Vitamin D in Female Patients \\ with Late Onset Acne
}

E.M.Sanad ${ }^{1}$, A.M.Hamed ${ }^{1}$, A.A.EL-Fallah ${ }^{2}$ and H.T.Khorshid ${ }^{1}$

${ }^{1}$ Dermatology and Andrology Dept., Faculty of Medicine, Benha Univ., Benha, Egypt

${ }^{2}$ Clinical and Chemical Pathology Dept., Faculty of Medicine, Benha Univ., Benha, Egypt

E-Mail: H.T.Khorshid@gmail.com

\begin{abstract}
Vitamin D is an essential hormone that is synthesized in the skin, it has a number of functions in addition to its well-known role as a modulator of calcium metabolism and homeostasis. It affects both the innate and adaptive immune system through its effects on $\mathrm{T}$ and $\mathrm{B}$ lymphocytes, dendritic cells, and macrophages, in dermatological diseases, it plays an important role as an immune modulator in atopic dermatitis, psoriasis, vitiligo, and alopecia. The aim of this study is to evaluate 25 -hydroxy Vitamin $\mathrm{D}$ in female patients with late onset acne comparing their levels with female patient with acne vulgaris, and also to correlate their levels with demographic data and clinical data of the disease. This study will include 30 female patients with acne vulgaris, 30 female patients with late onset acne and 30 patients with age and sex matched healthy volunteers as control group. They are selected from the Outpatient Clinic of Dermatology, Venereology and Andrology Department of Benha University Hospitals. Vitamin D serum levels were significantly lower in acne vulgaris patients than in control. The mean VIT-D serum levels were non-significant difference between late onset acne patients and their controls. Vitamin D deficiency may play an important role in the pathogenesis of acne vulgaris. Vitamin D supplements could be a helpful adjuvant in the treatment of acne vulgaris.
\end{abstract}

Keywords: Vitamin D, Skin, Lymphocytes and vitiligo.

\section{Introduction}

Acne is a common and complex skin disorder that distresses many patients because of its chronicity. Although multiple factors contribute to acne development, chronic inflammation is an important mechanism.

In addition, Propionibacterium acnes (P. acnes) triggers cytokine activation by Toll-like receptors, which means that the innate immune system is also important for acne development [1].

Acne is widely considered as chronic skin disease that primarily affects individuals going through puberty, with prevalence among this population of almost 95 percent. However, although acne is principally a disorder of adolescence, current research indicates that the prevalence of adult patients with acne is increasing. Three different groups of acne patients can be considered: preadolescent, adolescent, and postadolescent patients.

The production of androgens during puberty explains, in part, why acne vulgaris is so prevalent in this population regardless of socioeconomic status, nationality, or sex. The rising incidence of acne vulgaris in late adolescence is a global issue; however, it is unknown whether this increase is a result of higher prevalence of the Western diet, earlier onset of puberty, genetic drift, or a byproduct of unknown environmental factors.

Recent studies have shown an increasing number of cases of acne in adult. Local glandular metabolism turns some weak hormonal precursors into more active substances that increase the production of sebum, leaving these areas more prone to an increasing the colonization by Propionibacterium acnes.
25-hydroxyVitamin D is an essential hormone that is synthesized in the skin [8]. The two main forms of vitamin $\mathrm{D}$ are cholecalciferol and ergocalciferol.

Vitamin $D$ has a number of functions in addition to its well-known role as a modulator of calcium metabolism and homeostasis. It affects both the innate and adaptive immune system through its effects on $\mathrm{T}$ and $\mathrm{B}$ lymphocytes, dendritic cells, and macrophages.It is associated with systemic inflammatory diseases such as rheumatoid arthritis, systemic lupus erythematosus, and inflammatory bowel disease. In dermatological diseases, it plays an important role as an immune modulator in atopic dermatitis, psoriasis, vitiligo, and alopecia.

\section{Subjects and methods \\ 2.1 Subjects}

This study will include 30 female patients with acne vulgaris, 30 female patients with late onset acne and 30 patients with age and sex matched healthy volunteers as control group. They are selected from the Outpatient Clinic of Dermatology, Venereology and Andrology Department of Benha University Hospitals.

\subsubsection{Inclusion criteria}

The study will include female patients with acne vulgaris with age between (12-25) year's old and female patients with late onset acne with age over 25 years old.

\subsubsection{Exclusion criteria}

Any patients with any of the following conditions will be excluded from this study: Patients treated by systemic therapy for at least 1 
month or any topical therapy for at least 2 weeks prior to the study, Alcoholic patients, Patients on vitamin D supplement, Patients who take oral steroids, Patients with malabsorption disorders, kidney or liver diseases, and patients receiving phototherapy or photo-chemotherapy in the last 6 months and Pregnant and lactating females.

\subsubsection{Administrative design}

This study was approved by the Research Ethical Committee of Benha Faculty of Medicine.

\subsubsection{Ethical consideration}

Before taking blood samples, a written informed consent was taken from each patient and each subject in the control group.

\subsubsection{All participants were divided into three groups}

Group A: thirty female patients with acne vulgaris with age between $(12-25)$.

Group B: thirty female patients with acne vulgaris with age over 25 years old.

Group C: thirty age matched females as control group.

\subsection{Methods}

\subsection{1 patients will be subjected to:}

\subsubsection{History taking including:}

Occupation (indoor or outdoor and usage of sunscreen outdoor), course, distribution and duration of the disease, severity of the disease, presence of systemic disease, family history of the diseases and presence of any autoimmune disease.

\subsubsection{Clinical examination}

Complete general examination including the body mass index. Complete cutaneous examination; to evaluate the clinical type and scoring the severity of acne and the presence of post acne scar.

\subsubsection{Laboratory investigation}

Assessment of serum level of vitamin D was done by using ELISA technique.

\subsubsection{Sampling}

Five $(\mathrm{ml})$ of venous blood samples were taken from all studied subjects under strict sterile condition and collected in a serum separating tube. Sample was left for 30 minutes till clotting, then centrifuged. The separated serum was aliquoted and stored at $20^{\circ} \mathrm{C}$ till assay of vitamin D. To limit the effects of the seasonal fluctuation in 25hydroxy Vitamin D photosynthesis, patients was recruited during the same season.

\subsubsection{Assay principle}

This kit is an Enzyme-Linked Immunosorbent Assay (ELISA). The plate has been pre-coated with human 25-OH-D antibody. 25-OH-D present in the sample was added and bands to antibodies coated on the wells. And then biotinylated human 25-OHD Antibody was added and bands to 25-OH-D in the sample. Then Streptavidin-HRP was added and bands to the Biotinylated 25-OH-D antibody. After incubation unbound Streptavidin-HRP was washed away during a washing step. Substrate solution was then added and color developed in proportion to the amount of human 25-OH-D. The reaction was terminated by addition of acidic stop solution and absorbance was measured at $450 \mathrm{~nm}$.

\section{Results}

There was non-significant difference between acne vulgaris patients and control group regarding age $(\mathrm{P}=0.103)$ and $\mathrm{BMI}(\mathrm{P}=0.166)$ Table (1).

There was non-significant difference between late onset acne patients and their controls regarding age $(\mathrm{P}=0.129)$ and BMI $(\mathrm{P}=0.900)$ Table $(2)$.

There was significant difference between acne vulgaris and late onset acne patients regarding age $(\mathrm{P}<0.001)$, while There was non-significant difference between acne vulgaris and late onset acne patients regarding $\mathrm{BMI}(\mathrm{P}=0.609)$ Fig (1).

As regard clinical data, no statistically significant difference in course, types of acne, severity, family history of acne, special habits, presence of scar and family history of scar was found $(\mathrm{P}=0.197, \mathrm{P}=$ $0.317, \mathrm{P}=0.470, \mathrm{P}=0.542, \mathrm{P}=0.688, \mathrm{P}=0.417, \mathrm{P}=$ 0.100 respectively) between acne vulgaris and late onset acne patients except in duration which significantly increased in late onset acne than acne vulgaris patients $(\mathrm{P}=0.035)$ Fig (2).

The mean VIT D serum levels were significantly lower in acne vulgaris patients than their controls (Mean \pm SD: $14.296 \pm 7.175 ; 20.707 \pm 10.180 \mathrm{ng} / \mathrm{ml}$ respectively, $\mathrm{P}=0.018)$ ) Fig (3).

The mean VIT-D serum levels was nonsignificant difference between late onset acne patients and their controls ( $\mathrm{P}=0.370)$ Fig (4).

There was non-significant difference between acne vulgaris and late onset acne patients regarding VIT-D serum levels $(\mathrm{P}=0.135)$ Fig (5).

There were non-significant positive correlations between VIT-D serum levels and age, BMI, duration and severity of acne in acne vulgaris patients $(\mathrm{P}=$ 0.751, $\mathrm{P}=0.293, \quad \mathrm{P}=0.850$ and $\mathrm{P}=0.498$ respectively) Table (3)

There were non-significant negative correlations between VIT-D serum levels and age and duration of acne in late onset acne patients $(\mathrm{P}=0.788$ and $\mathrm{P}=$ 0.788 respectively) and there were-significant positive correlation between VIT-D serum levels and BMI and severity of acne in late onset acne patients $(\mathrm{P}=0.117$ and $\mathrm{P}=0.498$ respectively) Table (4).

There was no significant relation between VIT-D serum levels and course, types of acne, family history, special habits, presence of scar and family history of acne scar of acne vulgaris patients $(\mathrm{P}=$ $0.492, \mathrm{P}=0.492, \mathrm{P}=0.863, \mathrm{P}=0.483, \mathrm{P}=0.385$ and $\mathrm{P}=0.749$ respectively) Table (5). 
There was no significant relation between VIT-D serum levels and course, type of acne, family history, special habits, presence of scar and family history of acne scar of acne in late onset acne patients $(\mathrm{P}=$ $0.900, \mathrm{P}=0.826, \mathrm{P}=0.993, \mathrm{P}=0.544, \mathrm{P}=0.830$ and $\mathrm{P}=0.897$ respectively) Table (6).

Table (1) Comparison between acne vulgaris patients and their controls according to demographic data

\begin{tabular}{|c|c|c|c|c|c|c|c|c|c|}
\hline & \multirow[b]{3}{*}{$\begin{array}{l}\text { Range } \\
\text { Mean } \pm \text { SD }\end{array}$} & \multicolumn{6}{|c|}{ Groups } & \multicolumn{2}{|l|}{ T-Test } \\
\hline & & \multicolumn{3}{|c|}{ Acne vulgaris } & \multicolumn{3}{|c|}{$\begin{array}{c}\text { Control of Acne } \\
\text { vulgaris }\end{array}$} & \multirow{2}{*}{$\frac{\mathbf{t}}{-1.664}$} & \multirow{2}{*}{$\begin{array}{c}\begin{array}{c}\text { P- } \\
\text { value }\end{array} \\
0.103\end{array}$} \\
\hline $\begin{array}{l}\text { Age } \\
\text { (Years) }\end{array}$ & & $\begin{array}{c}13 \\
17.933\end{array}$ & $\begin{array}{l}- \\
\pm\end{array}$ & $\begin{array}{c}22 \\
2.434\end{array}$ & $\begin{array}{c}17 \\
19.133\end{array}$ & $\begin{array}{l}- \\
\pm\end{array}$ & $\begin{array}{c}24 \\
1.922\end{array}$ & & \\
\hline BMI & $\begin{array}{l}\text { Range } \\
\text { Mean } \pm \text { SD }\end{array}$ & $\begin{array}{c}22.1 \\
24.955\end{array}$ & $\begin{array}{l}- \\
\pm\end{array}$ & $\begin{array}{c}29.9 \\
1.852\end{array}$ & $\begin{array}{c}21.53 \\
24.180\end{array}$ & $\begin{array}{l}- \\
\pm\end{array}$ & $\begin{array}{l}26.35 \\
1.480\end{array}$ & 1.409 & 0.166 \\
\hline
\end{tabular}

Table (2) Comparison between late onset acne patients and their controls according to demographic data

\begin{tabular}{|c|c|c|c|c|c|c|c|c|c|}
\hline & \multirow[b]{3}{*}{$\begin{array}{l}\text { Range } \\
\text { Mean } \pm \text { SD }\end{array}$} & \multicolumn{6}{|c|}{ Groups } & \multicolumn{2}{|c|}{ T-Test } \\
\hline & & \multicolumn{3}{|c|}{ Late onset acne } & \multicolumn{3}{|c|}{ Control of Late onset acne } & \multirow{2}{*}{$\begin{array}{c}\mathbf{t} \\
-1.548\end{array}$} & \multirow{2}{*}{$\begin{array}{c}\text { P-value } \\
0.129\end{array}$} \\
\hline $\begin{array}{l}\text { Age } \\
\text { (Years) }\end{array}$ & & $\begin{array}{c}26 \\
28.733\end{array}$ & $\begin{array}{l}- \\
\pm\end{array}$ & $\begin{array}{c}36 \\
2.703\end{array}$ & $\begin{array}{c}27 \\
30.133\end{array}$ & $\begin{array}{l}- \\
\pm\end{array}$ & $\begin{array}{c}38 \\
3.159\end{array}$ & & \\
\hline BMI & $\begin{array}{l}\text { Range } \\
\text { Mean } \pm \text { SD }\end{array}$ & $\begin{array}{c}21.06 \\
24.699\end{array}$ & $\begin{array}{l}- \\
\pm\end{array}$ & $\begin{array}{l}29.09 \\
2.002\end{array}$ & $\begin{array}{c}21.6 \\
24.778\end{array}$ & $\begin{array}{l}- \\
\pm\end{array}$ & $\begin{array}{c}29.3 \\
1.943\end{array}$ & -0.126 & 0.900 \\
\hline
\end{tabular}

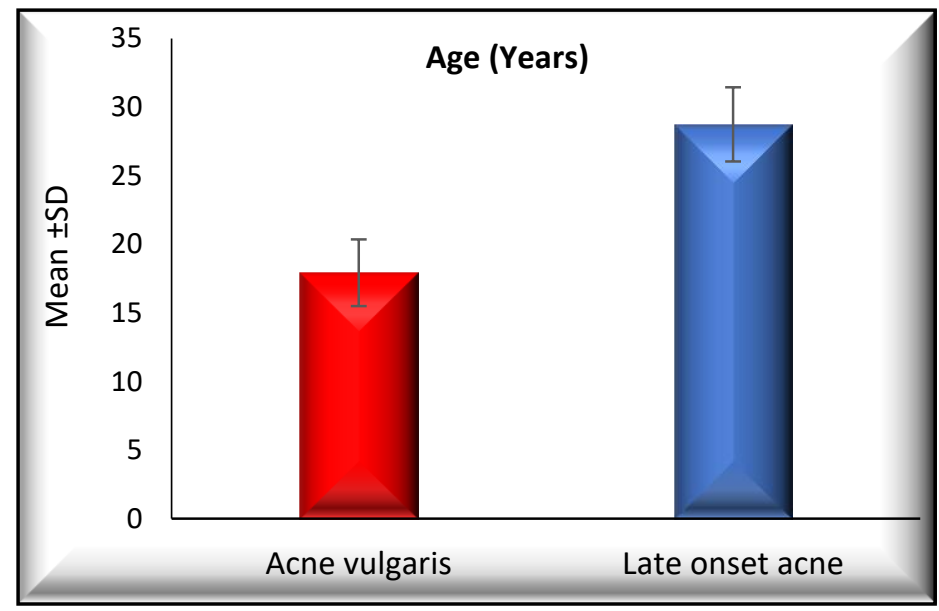

Fig (1) Age distribution in acne vulgaris and late onset acne patients.

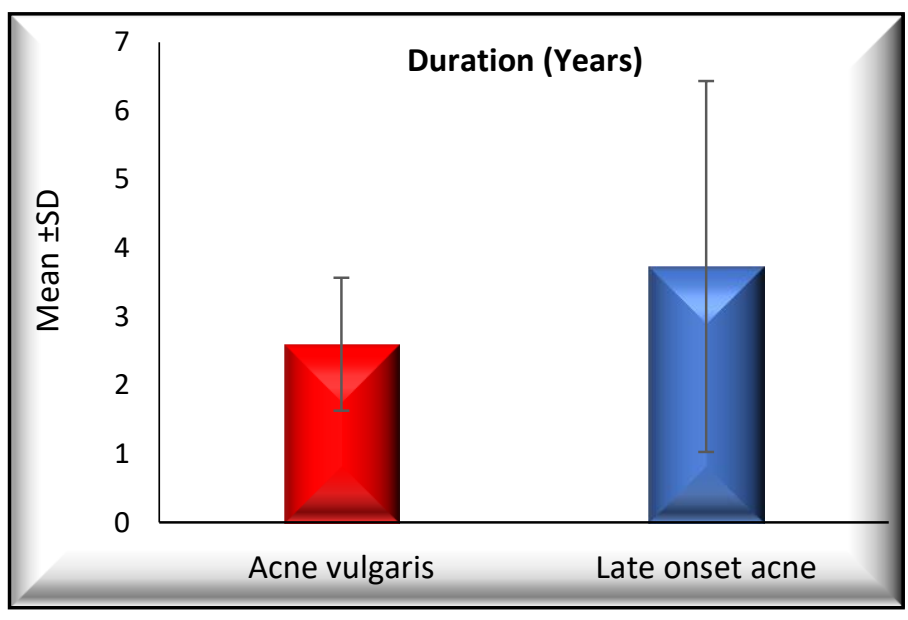

Fig (2) Duration distribution in acne vulgaris and late onset acne patients. 


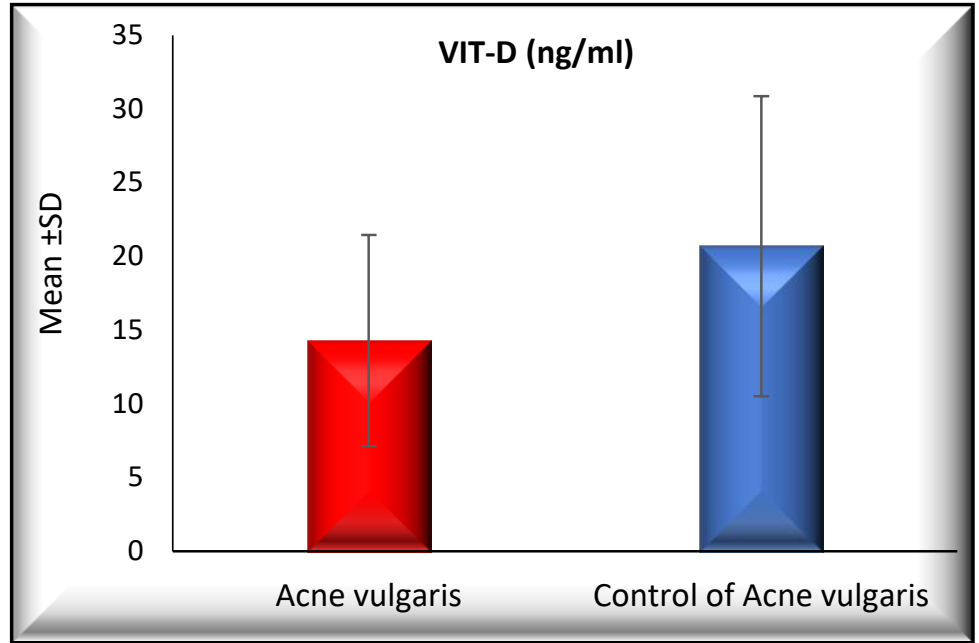

Fig (3) Comparison between acne vulgaris patients and their controls regarding VIT D serum levels $(\mathrm{ng} / \mathrm{ml})$.

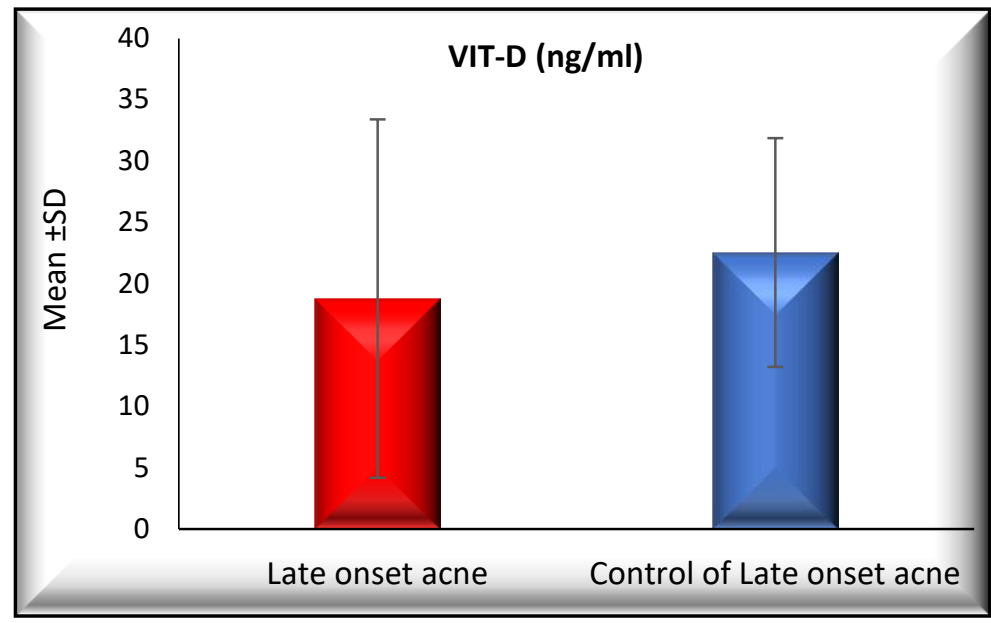

Fig (4) Comparison between late onset acne patients and their controls regarding VIT-D (ng/L).

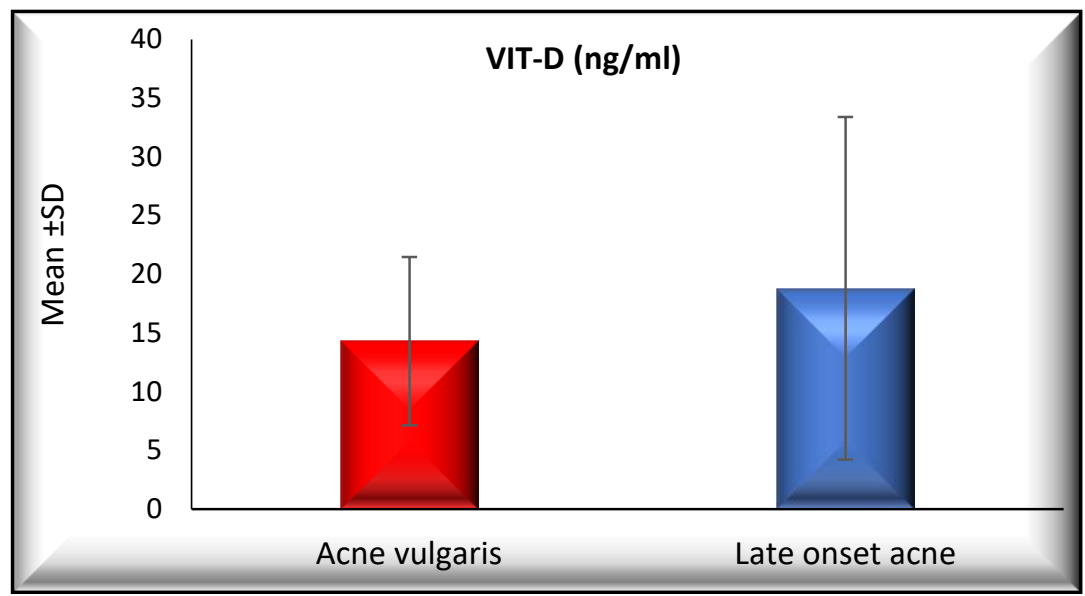

Fig (5) Comparison between Acne vulgaris and late onset acne patients regarding VIT-D (ng/L). 
Table (3) VIT-D serum levels and their correlations to Demographic data and duration of acne in acne vulgaris patients

\begin{tabular}{lcc}
\hline Correlations & \multicolumn{2}{c}{ VIT-D (ng/ml) } \\
\hline \multirow{2}{*}{ Acne vulgaris } & \multicolumn{2}{c}{ r } \\
\cline { 2 - 3 } Age (Years) & 0.060 & 0.751 \\
BMI & 0.199 & 0.293 \\
Duration (Years) & 0.036 & 0.850 \\
Severity & 0.717 & 0.498 \\
\hline
\end{tabular}

Table (4) VIT-D serum levels and their correlations to Demographic data and duration of acne in late onset acne patients

\begin{tabular}{lll}
\hline Correlations & & \\
\hline Late onset acne & VIT-D $(\mathrm{ng} / \mathrm{ml})$ & \\
Age (Years) & $\mathrm{r}$ & P-value \\
BMI & -0.051 & 0.788 \\
Duration (Years) & 0.292 & 0.117 \\
Severity & -0.051 & 0.788 \\
\hline
\end{tabular}

Table (5) Relation between VIT-D serum levels and clinical data of acne vulgaris patients

\begin{tabular}{llcccccc}
\hline Acne vulgaris & & \multicolumn{3}{c}{ VIT-D $(\mathbf{n g} / \mathbf{m l})$} & \multicolumn{3}{c}{ T-Test or ANOVA } \\
\hline & & $\mathrm{N}$ & Mean & \pm & SD & T or F & P-value \\
\cline { 2 - 7 } Course & Progress & 26 & 14.657 & \pm & 7.494 & \multirow{2}{*}{0.696} & 0.492 \\
& Stationary & 4 & 11.950 & \pm & 4.610 & & \\
Inflammatory & Non-inflammatory & 4 & 11.950 & \pm & 4.610 & & \\
Family History of & Inflammatory & 26 & 14.657 & \pm & 7.494 & -0.696 & 0.492 \\
Acne & Negative & 6 & 14.762 & \pm & 8.303 & & \\
Special habits & Negative & 24 & 14.180 & \pm & 7.061 & 0.175 & 0.863 \\
& Smoker & 26 & 13.927 & \pm & 6.984 & & \\
Presence of scar & Negative & 4 & 16.693 & \pm & 9.075 & -0.711 & 0.483 \\
& Positive & 18 & 13.349 & \pm & 6.037 & & \\
Family history of & Negative & 12 & 15.717 & \pm & 8.703 & -0.882 & 0.385 \\
scar & Positive & 17 & 13.920 & \pm & 7.173 & & \\
\hline
\end{tabular}

Table (6) Relation between VIT-D serum levels and clinical data of late onset acne patients

\begin{tabular}{|c|c|c|c|c|c|c|c|}
\hline \multirow[t]{2}{*}{ Late onset acne } & & \multicolumn{4}{|c|}{ VIT-D (ng/ml) } & \multicolumn{2}{|c|}{ T-Test or ANOVA } \\
\hline & & $\mathbf{N}$ & Mean & \pm & SD & $T$ or $F$ & P-value \\
\hline \multirow{2}{*}{ Course } & Progress & 22 & 18.585 & \pm & 15.483 & \multirow{2}{*}{-0.127} & \multirow{2}{*}{0.900} \\
\hline & Stationary & 8 & 19.363 & \pm & 12.754 & & \\
\hline \multirow{2}{*}{ Inflammatory } & Non-inflammatory & 7 & 17.700 & \pm & 12.805 & \multirow{2}{*}{-0.222} & \multirow{2}{*}{0.826} \\
\hline & Inflammatory & 23 & 19.125 & \pm & 15.347 & & \\
\hline \multirow{2}{*}{$\begin{array}{l}\text { Family History of } \\
\text { Acne }\end{array}$} & Negative & 8 & 18.831 & \pm & 16.213 & \multirow{2}{*}{0.009} & \multirow{2}{*}{0.993} \\
\hline & Positive & 22 & 18.778 & \pm & 14.370 & & \\
\hline \multirow{2}{*}{ Special habits } & Negative & 27 & 19.343 & \pm & 14.868 & \multirow{2}{*}{0.614} & \multirow{2}{*}{0.544} \\
\hline & Smoker & 3 & 13.833 & \pm & 13.169 & & \\
\hline \multirow{2}{*}{ Presence of scar } & Negative & 21 & 19.177 & \pm & 15.608 & \multirow{2}{*}{0.217} & \multirow{2}{*}{0.830} \\
\hline & Positive & 9 & 17.894 & \pm & 12.717 & & \\
\hline \multirow{2}{*}{$\begin{array}{l}\text { Family history of } \\
\text { scar }\end{array}$} & Negative & 23 & 18.987 & \pm & 15.311 & \multirow{2}{*}{0.130} & \multirow{2}{*}{0.897} \\
\hline & Positive & 7 & 18.153 & \pm & 13.011 & & \\
\hline
\end{tabular}




\section{Discussion}

Acne vulgaris a chronic inflammatory disease of the pilosebaceous unit (PSU) characterized by seborrhea, formation of comedones, erythematous papules, and pustules and less frequently by nodules, deep pustules, or pseudocysts [2]. The formation of microcomedons requires complex interplay of altered follicular keratinization, hyperplasia of sebaceous glands, and over colonization of sebaceous glands with propionibacterium acne (P. acne) [3].

Acne vulgaris is a multifactorial disease in which several factors have been implicated, including hormonal effects, follicular hyperkeratinization, proliferation of $\mathrm{P}$. acne, inflammatory, environmental and genetic factors [4]. Inflammation plays one of the main roles in the development of AV [5].

Acne vulgaris is a common skin disease in adolescents, with a prevalence of 80 to $90 \%$. During the previous 20 years, an increase of acne prevalence in adults, particularly in women over 25 years of age, has been described as a late onset acne [6]. The reasons for this are not fully understood; some authors postulate that hormonal factors related to modern life, increases in the search for dermatological care, and increased medical attention to this problem may be involved [7].

Late onset acne showed that in adult women the lesion distribution may be similar to that seen in adolescents, or be predominant in the mandibular and neck regions. The skin of adult acne patients is more sensitive than that of teenagers and prone to irritation with antiacne topical products. Adult acne is experienced as stressful and negatively impacts quality of life. This disease is highly refractory to treatment, with frequent recurrences.

25-hydroxyVitamin $\mathrm{D}$ is an essential hormone that is synthesized in the skin. The two main forms of vitamin $D$ are cholecalciferol and ergocalciferol [8].

Vitamin D has a number of functions in addition to its well-known role as a modulator of calcium metabolism and homeostasis. It affects both the innate and adaptive immune system through its effects on $\mathrm{T}$ and $\mathrm{B}$ lymphocytes, dendritic cells, and macrophages.

Identifying vitamin D receptors in human sebocytes and modulation of lipid and cytokine production by vitamin D suggest the possible association between vitamin $\mathrm{D}$ and acne pathophysiology.

The current study was designed to measure serum levels of 25-hydroxy vitamin D and to assess their role in acne vulgaris and late onset acne and to correlate their levels with demographic data and clinical data of the disease.

The present study was conducted on 30 patients suffering from acne vulgaris, 30 patients suffering from late onset acne, 15 patients with age and sex matched healthy subjects serving as a control group for acne vulgaris patients and 15 patients with age and sex matched healthy subjects serving as a control group for late onset acne patients.

This study was approved by the Research Ethical Committee of Benha Faculty of Medicine. Before taking blood samples, a written informed consents were taken from each patient or each subject in the control group. Each patient was subjected to full history took (regarding Occupations, course, distribution and duration of the disease, severity of the disease, presence of systemic disease, family history of the diseases), complete general examination (including the body mass index), complete cutaneous examination (evaluated the clinical type and scoring the severity of acne and the presence of post acne scar), investigations to determine the 25-hydroxy vitamin D serum levels using ELISA technique.

In the current study, as regard clinical data, no statistically significant difference in course, type of acne, severity, family history of acne, special habits, presence of scar and family history of scar was found $(\mathrm{P}=0.197, \mathrm{P}=0.317$, $\mathrm{P}=0.470, \mathrm{P}=0.542, \mathrm{P}=0.688, \mathrm{P}=0.417, \mathrm{P}=$ 0.100 respectively) between acne vulgaris and late onset acne patients except in duration which was significantly increased in late onset acne than acne vulgaris patients $(\mathrm{P}=0.035)$.

The significant difference in duration in our study could be explained by the small sample were taken and all the acne vulgaris patients were have a short course disease and most of the adult acne have long course disease and could be due to difference in hormonal state and life style between the two groups.

The result of the present study was in agreement with [9], they reported that postadolescent acne is very similar in severity to adolescent acne in up to 90 percent of women.

In the current study, the mean 25-hydroxy VIT D serum levels were significantly lower in acne vulgaris patients than their controls (Mean \pm SD: $14.296 \pm 7.175 ; 20.707 \pm 10.180$ $\mathrm{ng} / \mathrm{ml}$ respectively, $\mathrm{P}=0.018$ ).

The result of the present study was in agreement with [10], they reported that deficiency in $25(\mathrm{OH}) \mathrm{D}$ was detected in $48.8 \%$ of patients with acne, but in only $22.5 \%$ of the healthy controls.

The significant lowering in $25(\mathrm{OH}) \mathrm{D}$ in our study may be explained by modern lifestyles as indoor life and efforts to minimize 
sun exposure by using sunscreens and other sun avoidance strategies are considered one of the risk factors of vitamin D deficiency [11].

as regarding to the role of $25(\mathrm{OH}) \mathrm{D}$ and its receptors in regulating the processing of the long chain glycosylceramides that are critical for the skin barrier formation which is crucial in defending the skin, and inducing toll like receptor 2 (TLR2) and its co-receptor CD14, that initiate the innate immune response in skin [12]. Furthermore, vitamin D metabolites have an important role in regulating cellular functions and growth of sebaceous glands [13]. So this deficiency may play a role in acne vulgaris.

There were non-significant positive correlations between $25(\mathrm{OH}) \mathrm{D}$ serum levels and age, BMI, duration and severity of acne in acne vulgaris patients $(\mathrm{P}=0.751, \mathrm{P}=0.293, \mathrm{P}=$ 0.850 and $\mathrm{P}=0.498$ ) respectively.

The result of the present study was in agreement with [10], who stated that there is no significant correlation between serum vitamin D levels and age, BMI, duration and the severity in acne vulgaris patients.

The major source of vitamin $\mathrm{D}$ is exposure to sunlight, particularly the ultraviolet $B$ (UVB) component. It has been found that the optimum wavelength range for the production of vitamin D is between 295 and $300 \mathrm{~nm}$. This narrow range is sometimes referred to as DUV [14]. So the disagreement mentioned above was due to deficiency in exposure to sun light during cloudy weather in winter.

The results of the present study showed that the mean VIT-D serum levels was nonsignificant difference between late onset acne patients and their controls $(\mathrm{P}=0.370)$.

Also there was non-significant difference between acne vulgaris and late onset acne patients regarding VIT-D serum levels $(\mathrm{P}=$ $0.135)$

The result of present study was in agreement with [15]. They reported that there was non-significant difference between acne vulgaris and late onset acne patients regarding VIT-D serum levels.

There were non-significant relations between VIT-D serum levels and course, type of acne, family history, special habits, presence of scar, family history of acne scar and severity in late onset acne patients $(\mathrm{P}=$ $0.900, \mathrm{P}=0.826, \mathrm{P}=0.993, \mathrm{P}=0.544, \mathrm{P}=$ $0.830, \mathrm{P}=0.897$ and $\mathrm{P}=0.727$ respectively), and there were non-significant correlations between VIT-D serum levels and age, duration and $\mathrm{BMI}$ in late onset acne patients $(\mathrm{P}=0.788$, $\mathrm{P}=0.788$ and $\mathrm{P}=0.117$ respectively).

To the best of our knowledge, there were no previous studies that measured serum level of vitamin $\mathrm{D}$ in late onset acne patients regarding comparison between subjects and controls.

The reasons for this are not fully understood; some authors postulate that hormonal factors related to modern life, increases in the search for dermatological care, and increased medical attention to this problem may be involved [7].

\section{Conclusion}

Vitamin D deficiency may play an important role in the pathogenesis of acne vulgaris. Vitamin D supplements could be a helpful adjuvant in the treatment of acne vulgaris.

\section{References}

[1] J. Kim, Review of the innate immune response in acne vulgaris activation of Toll-like receptor 2 in acne triggers inflammatory cytokine responses. Dermatology, Vol. 211, PP. 193-198, 2005.

[2] NB. Simpson and WJ. Cunliffe, Rook's Textbook of Dermatology. Disorders of sebaceous glands, Burns T, Breathnach S, and Cox N, Eds. , PP. 43-78, Blackwell, Malden, Mass, USA, 7th edition, vol.18,PP.1- 7, 2004.

[3] H. Gollnick, AY. Finlay and N. Shear, Global alliance to improve outcomes in acne. Can we describe acne as a chronic disease? If so, how and when?Am. J. Clin .Dermatol.;vol.84,PP.922-930,2013.

[4] HC. Williams, RP. Dellavalle and S. Garner, Acne vulgaris. Lancet, Vol. 379, PP. 361-372, 2012.

[5] CC. Zouboulis and K. Degitz, Androgen action on human skin -from basic research to clinical significance. $\mathrm{J}$ Exp Dermatol, Vol. 14, PP. 5-10, 2004.

[6] K. Bhate and HC. Williams, "Epidemiology of acne vulgaris. ". The British journal of dermatology, Vol.168, PP. 474-485, 2013.

[7] RG. Albuquerque, MA. Rocha, E. Bagatin, S. Tufik, ML. Andersen. Could adult female acne be associated with modern life? Arch Dermatol Res, Vol. 306, PP. 683-8, 2014.

[8] S. Shah, MN. Islam and S. Dakshanamurthy, The molecular basis of vitamin D receptor and betacatenin cross regulation. Mol Cell, vol.21, PP.799-809, 2006.

[9] B. Dréno, A. Layton, CC. Zouboulis, JL. López-Estebaranz, Zalewska-Janowska A, et al. Adult female acne a new paradigm, Vol. 27, PP. 1063- 1070, 2013.

[10] V. Vanchinathan and HW. Lim, A dermatologist-s perspective on vitamin D. 
Mayo Clin Proc, Vol. 87, PP. 372-380, 2012.

[11] MR. Albert and KG. Ostheimer, The evolution of current medical and popular attitudes toward ultraviolet light exposure . J Am Acad Dermatol, Vol. 49, PP. 1096 $-1106,2003$.

[12] J. Schauber, RA. Dorschner and AB. Coda, Injury enhances TLR2 function and antimicrobial peptide expression through a vitamin D-dependent mechanism. J Clin Invest, Vol. 117, PP. 803-811, 2007.
[13] J. Reichrath, Vitamin D and the skin an ancient friend. Exp Dermatol, Vol.16, PP. 618-625, 2007.

[14] HF. Deluca, Evolution of our understanding of vitamin D. Nutr Rev, Vol. 66, PP. 73-87, 2008.

[15] CW. Choi, DH. Lee, HS. Kim, The clinical features of late onset acne compared with early onset acne in women. Eur Acad Dermatol Venereol, Vol.25, PP. 454- 461, 2011. 